\title{
Superfast Vocal Muscles Control Song Production in Songbirds
}

\author{
Coen P. H. Elemans ${ }^{1 \alpha_{*}}$, Andrew F. Mead ${ }^{2}$, Lawrence C. Rome ${ }^{2,3}$, Franz Goller ${ }^{1}$
}

1 Department of Biology, University of Utah, Salt Lake City, Utah, United States of America, 2 Department of Biology, University of Pennsylvania, Philadelphia, Pennsylvania, United States of America, 3 The Marine Biological Laboratory, Woods Hole, Massachusetts, United States of America

\begin{abstract}
Birdsong is a widely used model for vocal learning and human speech, which exhibits high temporal and acoustic diversity. Rapid acoustic modulations are thought to arise from the vocal organ, the syrinx, by passive interactions between the two independent sound generators or intrinsic nonlinear dynamics of sound generating structures. Additionally, direct neuromuscular control could produce such rapid and precisely timed acoustic features if syringeal muscles exhibit rare superfast muscle contractile kinetics. However, no direct evidence exists that avian vocal muscles can produce modulations at such high rates. Here, we show that 1) syringeal muscles are active in phase with sound modulations during song over $200 \mathrm{~Hz}, 2$ ) direct stimulation of the muscles in situ produces sound modulations at the frequency observed during singing, and that 3) syringeal muscles produce mechanical work at the required frequencies and up to $250 \mathrm{~Hz}$ in vitro. The twitch kinematics of these so-called superfast muscles are the fastest measured in any vertebrate muscle. Superfast vocal muscles enable birds to directly control the generation of many observed rapid acoustic changes and to actuate the millisecond precision of neural activity into precise temporal vocal control. Furthermore, birds now join the list of vertebrate classes in which superfast muscle kinetics evolved independently for acoustic communication.
\end{abstract}

Citation: Elemans CPH, Mead AF, Rome LC, Goller F (2008) Superfast Vocal Muscles Control Song Production in Songbirds. PLoS ONE 3(7): e2581. doi:10.1371/ journal.pone.0002581

Editor: Pier Francesco Ferrari, Università di Parma, Italy

Received March 19, 2008; Accepted May 28, 2008; Published July 9, 2008

Copyright: ( $) 2008$ Elemans et al. This is an open-access article distributed under the terms of the Creative Commons Attribution License, which permits unrestricted use, distribution, and reproduction in any medium, provided the original author and source are credited.

Funding: This study was funded by NIH DC04390 and DC06876 to FG, and NIH AR38404-20 and NIH AR46125 to LCR. The work was also supported by a grant from the Pennsylvania Department of Health to LCR. The Department specifically disclaims responsibility for any analyses, interpretations, or conclusions.

Competing Interests: The authors have declared that no competing interests exist.

*E-mail: coen@biology.sdu.dk

a Current address: Institute of Biology, University of Southern Denmark, Odense M, Denmark

\section{Introduction}

Some of the most complex vocal communication signals in the animal kingdom are produced by songbirds [1], whose songs often contain long sequences of rapidly modulated sound elements [2]. Rapid acoustic modulations ( $<10 \mathrm{~ms}$ ) during song can arise from passive interactions between the two independent (i.e. left and right) sound generators in the vocal organ - the syrinx [3] and intrinsic nonlinear dynamics of sound generating structures [e.g. 4-7]. However, many acoustic features of song correlate with neural [814] and electromyographic (EMG) activity [15-19], which suggests the possibility of direct neuromuscular control of the syrinx.

Indirect evidence from EMG recordings in brown thrashers (Toxostoma rufum) indicates that sound modulations up to $125 \mathrm{~Hz}$ correlate with muscle activity [17]. Furthermore, the variation in temporal characteristics of song in zebra finches (Taenopygia guttata) correlates with variation in the spiking patterns of neurons in premotor brain nuclei $[8,9,11,12,14]$, which suggests that the temporal precision of the CNS can be expressed at the behavioral level of song production. Both findings are consistent with very fast muscular control of the vocal production system of songbirds. However, to actuate these rapid changes, songbirds would need to have evolved syringeal muscles with superfast contractile kinetics. This rarely evolved trait would enable them to produce positive work over $100 \mathrm{~Hz}$ [20]. To our knowledge no direct evidence exists that avian vocal muscles can produce modulations at such high rates.
To assess how high temporal precision in the central premotor song circuits is translated into equally high precision at the behavioral level, we need to make a direct determination of temporal performance limits of vocal muscular control in songbirds. By conducting a series of experiments at different levels of organization, we show that the vocal muscles of songbirds exhibit superfast contractile kinetics and can generate acoustic modulations up to $250 \mathrm{~Hz}$.

\section{Results}

European starlings (Sturnus vulgaris) have a complex learned song $[21,22]$, which contains many fast modulations. Some syllables contain amplitude modulated "buzzes" (100-125 Hz) and other modulations up to $200 \mathrm{~Hz}$ (Figure 1). In order to test whether these modulations could be the result of direct muscular control, we measured electromyographic (EMG) activity of the syringeal muscles in freely singing starlings (see Supporting Information, Methods S1). The main muscle causing amplitude modulations by regulating airflow is the $m$. tracheobronchialis dorsalis (dTB) [17]. In vivo recordings of dTB activity in freely singing starlings showed that amplitude modulation of the produced sound was accompanied by synchronized dTB activity, suggesting active control (Figure 1B). The dTB showed activity bursts that correlated with sound amplitude at intervals as short as $4.6 \mathrm{~ms}$, which is equivalent to a repetition rate of $218 \mathrm{~Hz}$ (Figure 1C). If syringeal 


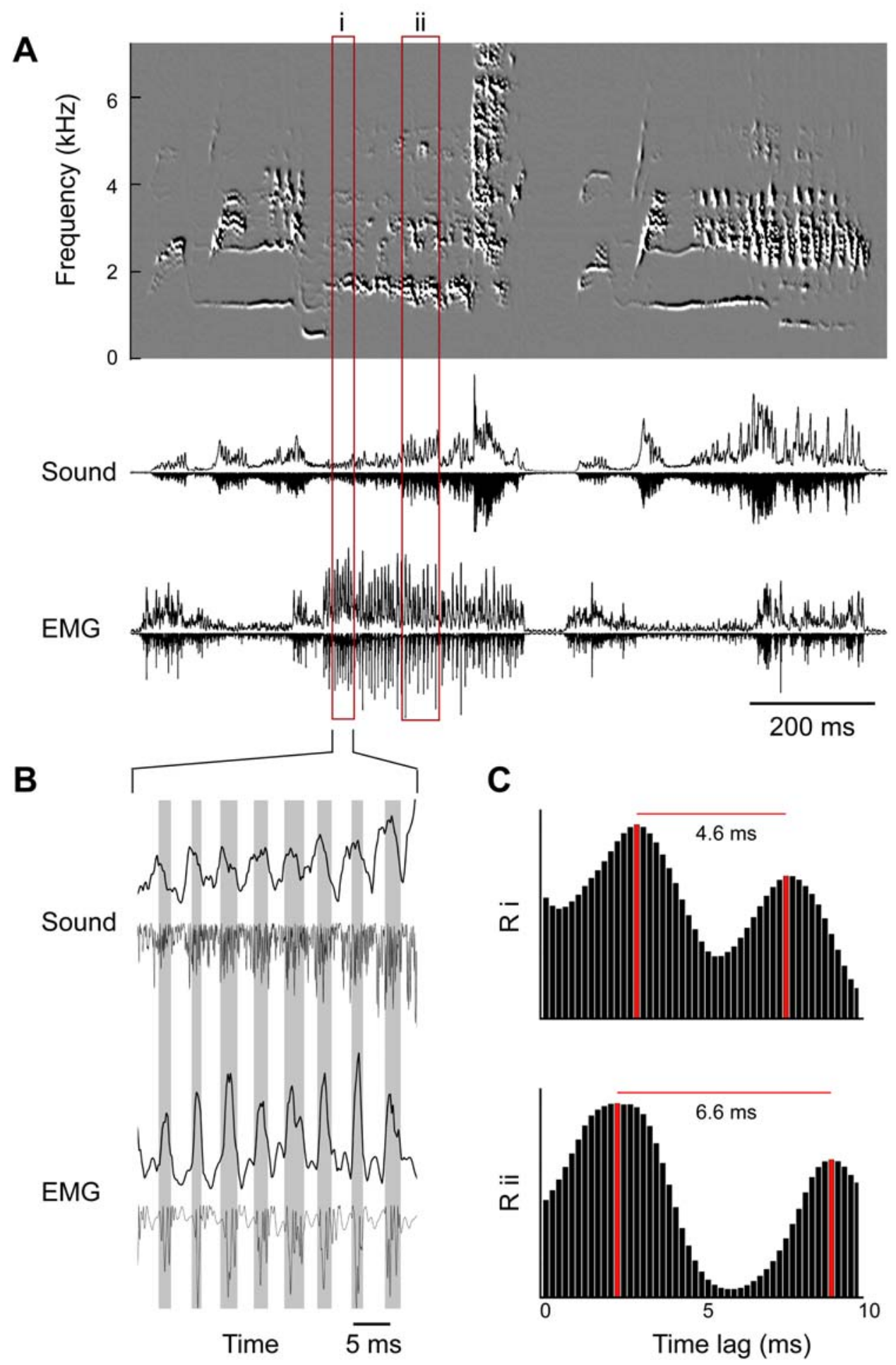

Figure 1. Song of starling exhibits fast modulations that correlate with muscle activity. (A) Spectral derivative plot [45] (top), oscillogram of sound and EMG activity of $m$. tracheobronchialis dorsalis (dTB). (B) Expanded time scale of segment $\mathrm{i}$. The rate of modulation of the sound amplitude is paralleled by peaks in muscle activity (shaded areas). Positive traces; integrated values (time constant 0.2 ms), negative traces; half-wave rectified values. (C) Cross-correlations (R) of integrated sound amplitude and EMG activity signals of segments $i$ and ii show a temporal link between EMG activity and sound modulation. The segments $\mathrm{i}$ and ii are indicated in (A). The distance between the local peaks in the bar diagrams equals the period of the signals. The periods are 4.6 and $6.6 \mathrm{~ms}$ in segment $\mathrm{i}$ and ii respectively, which is equivalent to repetition rates of 218 and $152 \mathrm{~Hz}$. EMG; electromyogram of dTB, Sound; sound oscillogram.

doi:10.1371/journal.pone.0002581.g001 
muscles cause these sound modulations, it requires that they can produce work and modulate syringeal parameters at these high rates.

To determine whether the muscles are indeed capable of this performance, we measured the in vitro performance of syringeal muscles in European starlings and zebra finches. We used isolated fibre bundles of the adductor muscle dTB in starlings and the abductor muscle $m$. tracheobronchialis ventralis (vTB) in zebra finches.

The twitch half-times measured $3.23 \pm 0.44 \mathrm{~ms}$ in male starling $(\mathrm{N}=12), 2.93 \pm 0.79 \mathrm{~ms}$ in female starling $(\mathrm{N}=3), 3.73 \pm 0.68 \mathrm{~ms}$ in male zebra finch $(\mathrm{N}=8)$ and $7.08 \pm 0.79 \mathrm{~ms}$ for female zebra finch $(\mathrm{N}=3)$ at $41.4^{\circ} \mathrm{C}$. The twitch half-times were not significantly different between males and females in starlings $(\mathrm{t}-$ test: $p=0.5802$, combined measurement: $3.23 \pm 0.44 \mathrm{~ms}, \mathrm{~N}=15$ ), but were significantly different between males and females in zebra finches (t-test; $p<0.01$; Figure 2A).

In some bird species, song control is lateralized [23-27] with a tendency to predominantly generate amplitude (and frequency) modulations on the right side in the brown thrasher [17]. Therefore we focused on obtaining muscle preparations from the right side of the syrinx (See Supporting Information, Methods $\mathrm{S} 1)$. However, we also obtained a number of muscle preparations from the left side of the syrinx (three for male starling and two for male zebra finch). The twitch half-times did not differ significantly for starling (t-test, $p=0.499$; lumped data males and females) or zebra finch (t-test, $p=0.969$; males only).

In starlings, the dTB developed isometric force from $10 \%$ to $100 \%$ in $1.74 \pm 0.32 \mathrm{~ms}(\mathrm{~N}=15)$. In one preparation, the twitch half-time was as short as $1.6 \mathrm{~ms}$ and it developed force from $10 \%$ to $100 \%$ in $1.03 \mathrm{~ms}$. Twitches were still completely separate at

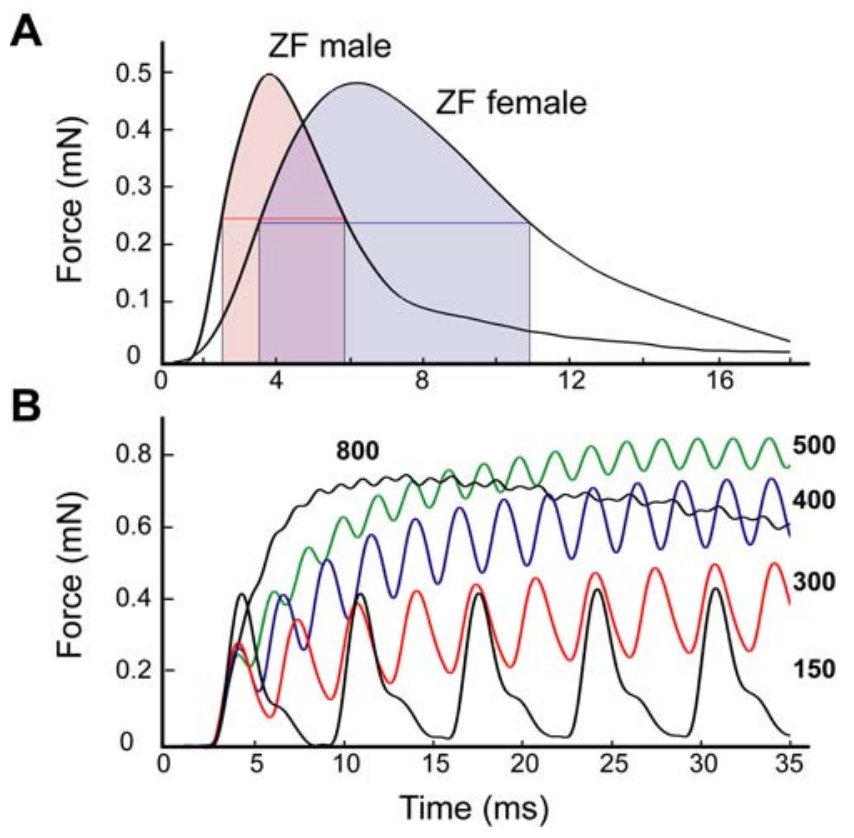

Figure 2. In vitro isometric properties of syringeal muscles exhibit superfast twitch kinetics. (A) Twitch characteristic of male and female zebra finch $m$. tracheobronchialis ventralis demonstrate extremely fast rise, and decay times. In zebra finches, syringeal muscle performance is sexually dimorphic. (Twitch half time $3.73 \pm 0.68 \mathrm{~ms}$ (male, $\mathrm{N}=8$ ) and $7.08 \pm 0.79 \mathrm{~ms}$ (female, $\mathrm{N}=3$ ). t-test; $\mathrm{p}<0.01$ ) (B) Twitches of male starling $m$. tracheobronchialis dorsalis are completely separated at $150 \mathrm{~Hz}$. Force summates at faster stimulation, and the tetanic fusion is not complete until $800 \mathrm{~Hz}$. The stimulation frequencies corresponding to the curves are indicated in bold.

doi:10.1371/journal.pone.0002581.g002
$150 \mathrm{~Hz}$ stimulation frequency and tetanic fusion was not complete until $600-800 \mathrm{~Hz}$ in all preparations (Figure 2B).

Isometric measurements, however, do not provide evidence whether the muscles can produce work at the high cycle frequencies as suggested by our in vivo measurements. To modulate sound, muscle must be able to perform mechanical work at the modulation frequency. Non-isometric measurements in which we subjected the muscles to various strain cycles and stimulation regimes (the workloop technique [28]) revealed that syringeal muscles indeed produce positive work and power at cycle frequencies up to $250 \mathrm{~Hz}$ (Figure 3). These data establish that syringeal muscles have the contractile potential to actuate syringeal elements as fast as $250 \mathrm{~Hz}$.

Because measurements on isolated fiber bundles do not take into account additional elasticity and mass of the in situ configuration, we tested whether this extreme modulation performance is attainable by the whole muscle in the intact syrinx. We electrically stimulated the dTB and vTB at different rates and measured their capacity to modulate airflow in anaesthetized male starlings (Methods S1, Figure S1). These measurements showed that also in situ, syringeal gating muscles could modulate syringeal airflow up to $250 \mathrm{~Hz}$ (Figure 4A,B). When flow was increased above the phonation threshold, muscle stimulation caused amplitude modulation in the radiated sound (Figure 4C).

\section{Discussion}

We present direct evidence that songbird have superfast syringeal muscles, which can modulate song acoustics up to $250 \mathrm{~Hz}$. The extremely fast performance of isolated muscle fibers in vitro translates into very rapid modulation of syringeal airflow and sound amplitude in the biomechanically relevant setting of the intact syrinx in situ. Both tests indicate clearly that the presumed direct muscular control inferred from EMG activity during spontaneous song in vivo is well within the temporal performance capabilities of syringeal muscles, and therefore most likely indicates direct active neuromuscular control of sound modulation in spontaneously singing birds.

The performance of syringeal muscle ranks them among the fastest known vertebrate muscles [20]. With twitch contraction halftimes of $3.23 \pm 0.44 \mathrm{~ms}(\mathrm{~N}=15)$ and $3.73 \pm 0.68 \mathrm{~ms}(\mathrm{~N}=8)$ for the adductor muscle dTB in starling and the abductor muscle vTB in male zebrafinch, respectively, these highly specialized muscles attain the fastest measured isometric twitch kinematics of any vertebrate muscle to our knowledge. The isometric twitch characteristics of syringeal muscles in a non-songbird, the ring dove (Streptopelia risoria), were previously shown to be close to other superfast vertebrate muscles [15], but their performance limits (i.e., capability of performing mechanical work at high frequencies) were not explored [16]. With twitch half-times around $10 \mathrm{~ms}$ [15], the syringeal muscles in ring doves are much slower than the syringeal muscles of songbirds and can not be fast enough to control the modulation rates we observe in songbirds. Consistent with this, ring doves exhibit modulation rates of only $25 \mathrm{~Hz}$ during their vocalizations [16].

The extremely rapid activation and relaxation phases of syringeal muscle contraction require that multiple ultra-structural and molecular systems must be in place and work in concert [20]. It is currently unknown how the extremely rapid kinetics is achieved in syringeal muscles. Because both activation and relaxation are fast, we can expect that the processes of $\mathrm{Ca}^{2+}$ release and cross-bridge attachment during the activation cycle, and $\mathrm{Ca}^{2+}$ reuptake, $\mathrm{Ca}^{2+}$ unbinding from troponin and cross- 

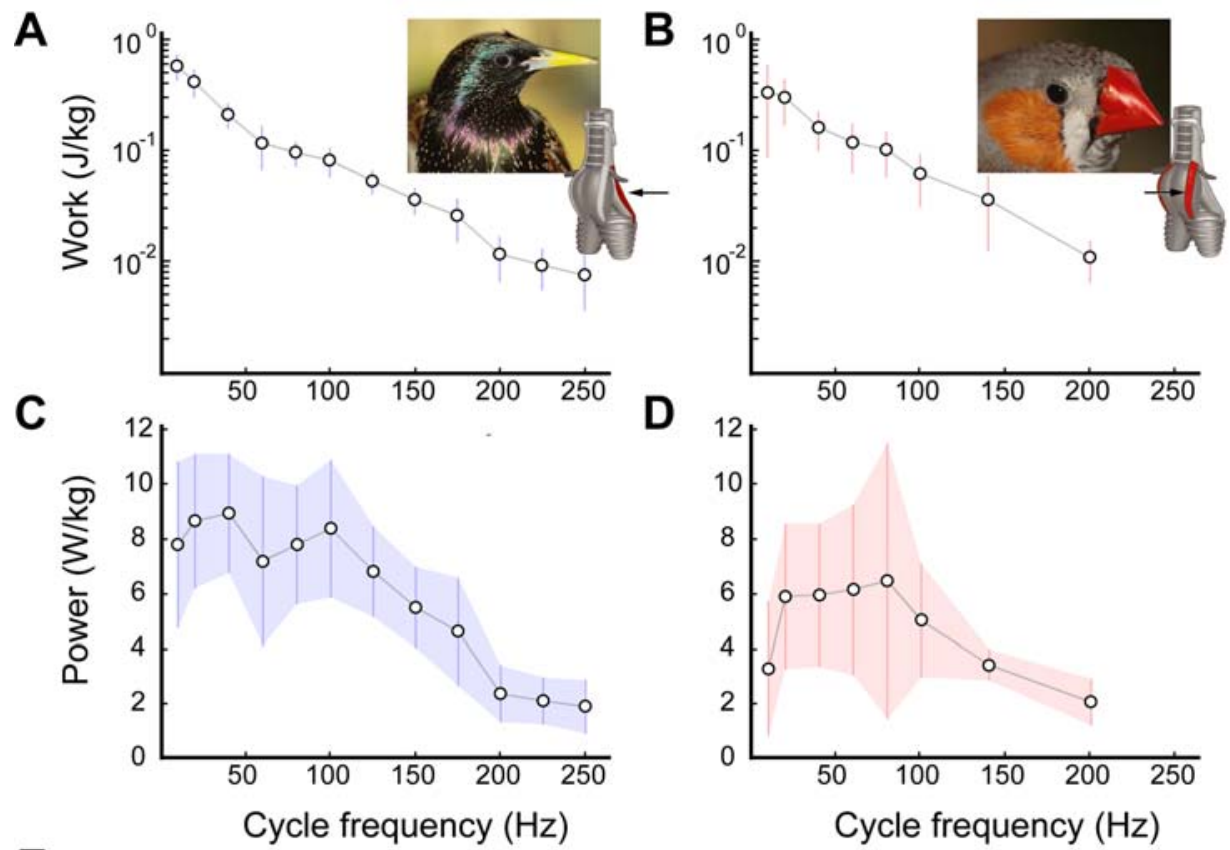

E

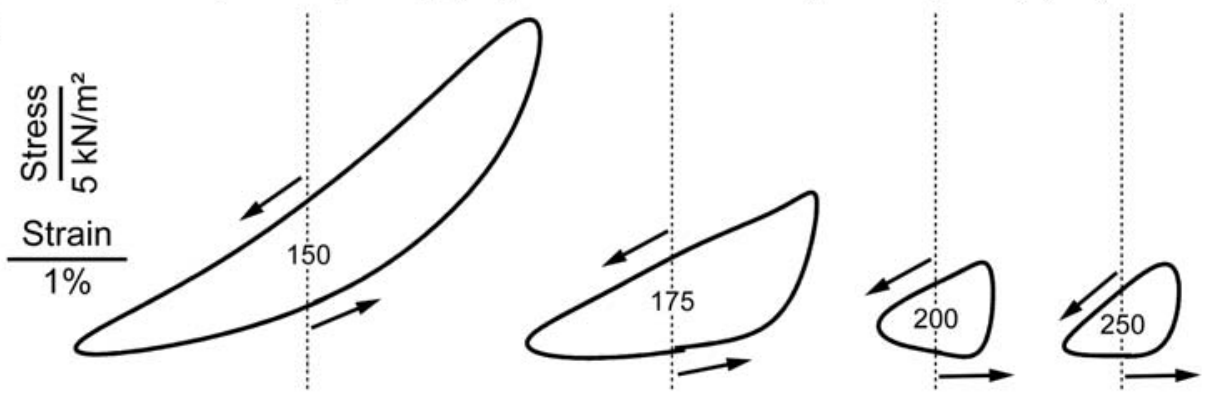

Figure 3. Superfast syringeal muscles produce positive work and power up to $\mathbf{2 5 0} \mathbf{~ H z}$ in vitro. (A) Work and (C) power production of male starling $m$. tracheobronchialis dorsalis ( $\mathrm{dTB}, \mathrm{N}=5)$. (B) Work and ((D) power production of male zebra finch $m$. tracheobronchialis ventralis $(\mathrm{vTB}, \mathrm{N}=6)$. Plotted values are mean \pm S.D. The insets show the bird species and the position of the dTB and vTB muscle on a schematic of the songbird's syrinx (modified after [46]). The arrows indicate which muscle is being tested. (E) Active workloops of starling dTB at 150, 175, 200 and 250 Hz. Dotted vertical lines indicate zero strain (= resting length). Arrows indicate lengthening (pointing right) and shortening (pointing left) portions of the workloop.

doi:10.1371/journal.pone.0002581.g003

bridge detachment during deactivation $[20,29,30]$ are extremely fast. Syringeal muscles operate at a high temperature of $41^{\circ} \mathrm{C}$. The expected increase in kinetics induced by these high temperatures may not require as extreme adaptations as found in ectothermic animals, such as toadfish, who call at temperatures from $15-25^{\circ} \mathrm{C}$. Nonetheless, syringeal muscles are much faster than locomotory muscles and likely involve novel myosin isoforms.

Superfast muscle is a muscle type that has only sporadically evolved, but appears in some vertebrate classes. The bestdocumented cases are the swimbladder muscles in various fishes [29-33] and the tail shaker muscles in rattle snakes [29,34]. Fast muscles have been observed in mammals: laryngeal muscle [35], and extraocular muscles e.g. [36,37], but mechanical measurements are yet to place them in the same league as the superfast muscles described above. The presence of superfast muscles in the avian vocal organ adds another independent case where these highly specialized muscles seem to have evolved in a sound production system. The function of the vocal muscles in mammals and birds differs from that of the swimbladder and tailshaker muscles. In mammals and birds, sound is produced by airflowinduced vibration of vocal folds in the larynx or labia in the syrinx, respectively. Vocal muscles of the mammalian larynx and avian syrinx do not generate sound pulses with each contraction, but they adjust vocal parameters that cause modulation of the flowinduced oscillations of vocal folds and labia.

Cross-bridge kinetics [30] and space constraints at the muscle ultra-structural level dictate a trade-off between force production and maximal attainable frequency at which positive work can be produced $[31,38,39]$. This trade-off makes only certain biomechanical systems amenable to deriving benefits from superfast muscles. Motor systems under selection for speed therefore need to reduce actuator mass. The energy content of sound waves is low and the production and modulation of sound generally involves manipulation of low masses (e.g. swimbladder, rattle, syringeal and glottal structures), compared with much heavier skeletal elements (e.g. appendages). In contrast to muscles in locomotory systems [40], muscles in sound production systems appear to be optimized for speed and not power [31].

We show that motor performance of syringeal muscles in zebra finches is sexually dimorphic: the twitch characteristics of a main gating muscle vTB are significantly different between females and males, with the vTB of the females being almost two times slower. 


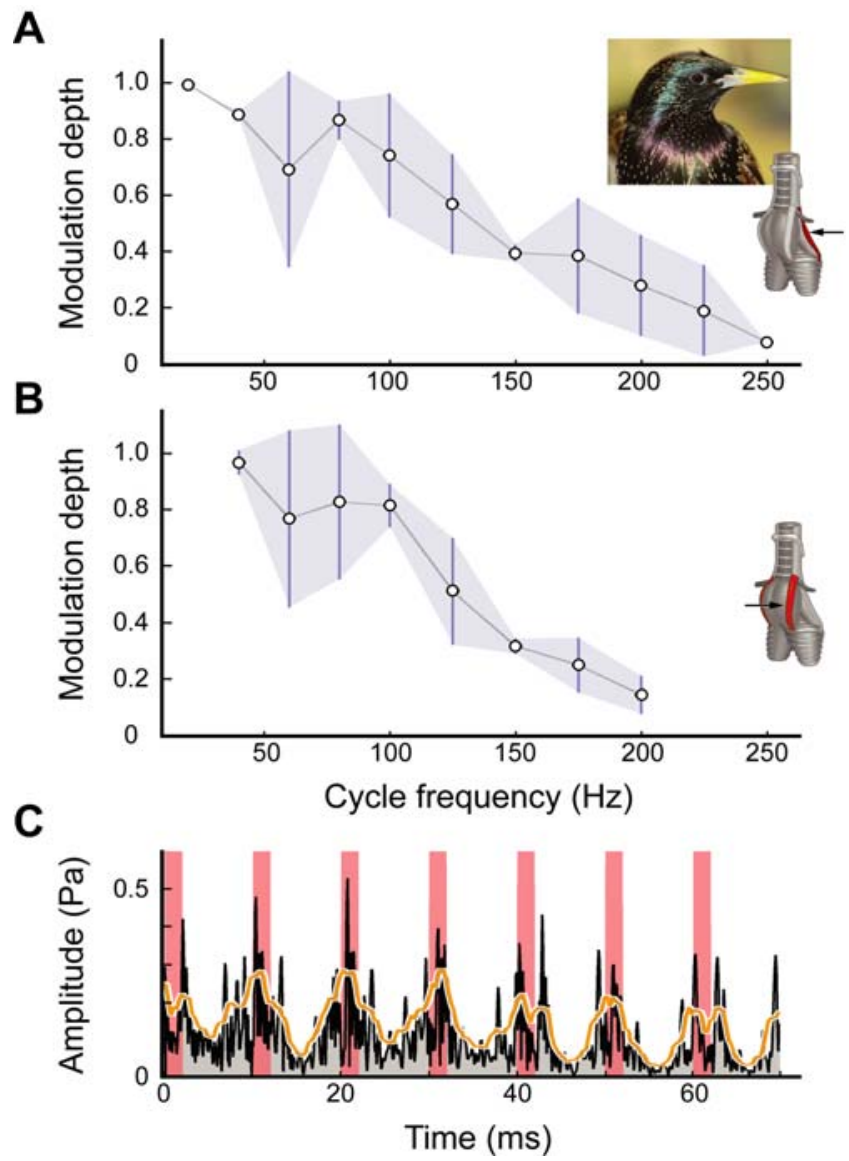

Figure 4. Stimulation of syringeal muscles causes tracheal flow and sound modulation. In situ muscle stimulation of syringeal muscles (A) dTB $(\mathrm{N}=3)$ and $(\mathrm{B})$ vTB $(\mathrm{N}=3)$ modulates tracheal flow up to $250 \mathrm{~Hz}$. Values are mean \pm S.D. The insets show the position of the dTB and VTB muscle on a schematic of the songbird's syrinx (modified after [46]). The arrows indicate which muscle is being tested. (C) Sound amplitude of vocalization during dTB stimulation at $100 \mathrm{~Hz}$. The sound amplitude drops following muscle stimulation (red areas). Black trace; half-wave rectified sound signal, orange trace; integrated sound signal (time constant $2 \mathrm{~ms}$ ).

doi:10.1371/journal.pone.0002581.g004

This sexually dimorphic performance could arise from any of the above-mentioned muscular (ultra-) structural or molecular systems that affect contraction speed. In starlings however, no sexual dimorphism is found in muscle performance. These results are paralleled by singing behavior of these two species: in zebra finches only the males sing [41,42], whereas in starlings both males and females sing [21].

The neuromuscular control of song production in the syrinx is a well-known example of lateralized behavior [23-27,43]. Despite the low number of preparations, our data suggest that there is no lateralization in syringeal muscle twitch performance in the two investigated species. Therefore both sides of the syrinx seem to have an equal potential to modulate labial vibrations.

Extremely rapid transitions during song - in the order of $1 \mathrm{~ms}$ can be caused by intrinsic dynamics of the syrinx [4]. In this study we provide direct evidence that songbird syringeal muscles are sufficiently fast to actively modulate acoustic parameters at these same high rates. Syringeal muscles of starlings generate full force within $1.74 \pm 0.32 \mathrm{~ms}(\mathrm{~N}=15)$, which allows direct adjustments of vocal output in the millisecond range. In addition, with the use of fast syringeal muscles timing of sound onset can be controlled with high precision. The vocal production system of birds operates with high fidelity and is capable of millisecond temporal precision in portions of the song $[8,10-12]$. Superfast vocal muscles represent the mechanical actuator to translate the temporal precision in neural motor activity into similar precision in the behavioral output.

\section{Materials and Methods}

\section{In vivo muscle activity}

Syringeal muscle activity was measured in freely singing male starlings (Sturnus vulgaris) as previously described [16-19,44]. All experiments were in accordance with the Institutional Animal Care and Use Committee (IACUG) of the University of Utah, Salt Lake City, USA. Methods are described in detail in the Online Supporting Information, Methods S1.

\section{In vitro muscle performance}

The work and power generated by syringeal muscles was determined using the workloop technique on isolated muscle fibre bundles as previously described [16,28,29,31]. In starlings, we isolated fibre bundles along the surface of musculus tracheobronchialis dorsalis ( $\mathrm{dTB}$ ). In zebra finches, we isolated fibre bundles of the musculus tracheobronchialis ventralis (vTB). Experiments were performed at the University of Pennsylvania, in October 2006 (zebra finches) and May 2007 (starlings) according to regulations by the IACUC, University of Pennsylvania, Philadelphia, USA.

\section{In situ muscle stimulation and flow modulation}

The effect of direct muscle stimulation (dTB) on syringeal airflow was measured on anaesthetized starlings in situ. Airflow above the syrinx was monitored with a custom-built direction sensitive flow probe, consisting of plastic tubing with two heated microbead thermistors in the lumen of the tube. Experiments were performed at the University of Utah, June 2007. All experiments were in accordance with the IACUC of the University of Utah, Salt Lake City, USA. A detailed description of the Materials and Methods can be found in the Supporting Information. Methods S1.

\section{Supporting Information}

Methods S1 Supplemental Information: Materials and Methods.

Found at: doi:10.1371/journal.pone.0002581.s001 (0.06 MB DOC)

Figure S1 Flow modulation in the trachea following electrical stimulation of the syringeal muscles.

Found at: doi:10.1371/journal.pone.0002581.s002 (1.10 MB TIF)

\section{Acknowledgments}

The authors wish to thank B. Cooper for discussion, assistance with the in vivo data collection and advice on LabView programming, J. AndrewsLabenski for technical assistance, M. Schmidt for discussion, comments on a previous version of the manuscript and kindly providing zebra finches, $\mathrm{J}$. Raksin for suggesting to look at twitch characteristics of female zebra finches, R. Blake, B. Sweeten, A. Baker, M. J. van Schoonhoven and S. Osmek (Seattle Tacoma Airport) for field-assistance or attempts to capture starlings, and the reviewers for helpful and constructive comments on the manuscript.

\section{Author Contributions}

Conceived and designed the experiments: FG GE AM LR. Performed the experiments: FG CE AM LR. Analyzed the data: FG CE AM LR. Contributed reagents/materials/analysis tools: FG LR. Wrote the paper: FG CE AM LR. 


\section{References}

1. Marler P, Slabbekoorn H (2004) Nature's music: The science of birdsong. New York: Academic Press.

2. Greenewalt CH (1968) Bird Song: Acoustics and Physiology. Smithsonian Institute Washington DC.

3. Nowicki S, Capranica RR (1986) Bilateral syringeal interaction in vocal production of an oscine bird sound. Science 231: 1297-1299.

4. Fee MS, Shraiman B, Pesaran B, Mitra PP (1998) The role of nonlinear dynamics of the syrinx in the vocalisations of a songbird. Nature 395: 67-71.

5. Fitch WT, Neubauer J, Herzel H (2001) Calls out of chaos: the adaptive significance of nonlinear phenomena in mammalian vocal production. Animal Behaviour 63: 407-418.

6. Tokuda I, Riede T, Neubauer J, Owen MJ, Herzel H (2002) Nonlinear analysis of irregular animal vocalizations. J Acoust Soc Am 111: 2908-2919.

7. Wilden I, Herzel H, Peters G, Tembrock G (1998) Subharmonics biphonation and deterministic chaos in mammal vocalisation. Bioacoustics 9: 171-196.

8. Chi Z, Margoliash D (2001) Temporal precision and temporal drift in brain and behavior of zebra finch song. Neuron 32: 899-910.

9. Fee MS, Kozhevnikov AA, Hahnloser RH (2004) Neural mechanisms of vocal sequence generation in the songbird. Ann NY Acad Sci 1016: 153-170.

10. Glaze CM, Troyer TW (2007) Behavioral measurements of a temporally precise motor code for birdsong. J NeuroSci 27: 7631-7639.

11. Hahnloser RH, Kozhevnikov AA, Fee MS (2002) An ultra-sparse code underlies the generation of neural sequences in a songbird. Nature 419: 65-70.

12. Leonardo A, Fee MS (2005) Ensemble coding of vocal control in birdsong. J NeuroSci 25: 652-661.

13. Schmidt M (2003) Pattern of interhemispheric synchronization in HVC during singing correlates with key transitions in the song pattern. J Neurophysiol 90: 3931-3949.

14. Yu AC, Margoliash D (1996) Temporal hierarchical control of singing in birds. Science 273: 1871-1875.

15. Elemans CPH, Spierts ILY, Muller UK, van Leeuwen JL, Goller F (2004) Superfast muscles control dove's trill. Nature 431: 146.

16. Elemans CPH, Spierts ILY, Hendriks M, Schipper H, Müller UK, van Leeuwen JL (2006) Syringeal muscles fit the trill in ring doves (Streptopelia risoria L.). J Exp Biol 209: 965-977.

17. Goller F, Suthers RA (1996) Role of syringeal muscles in gating airflow and sound production in singing brown thrashers. J Neurophysiol 75: 867-876.

18. Goller F, Suthers RA (1996) Role of syringeal muscles in controlling the phonology of bird song. J Neurophysiol 76: 287-300.

19. Vicario DS (1991) Contributions of syringeal muscles to respiration and vocalization in the zebra finch. J Neurobiol 22: 63-73.

20. Rome LC (2006) Design and function of superfast muscle: new insights into the physiology of skeletal muscle. Ann Rev Physiol 68: 193-221.

21. Hausberger M (1997) in Social Influences on Vocal Development Snowdon CT, Hausberger M, eds. Cambridge, UK: Cambridge University Press. pp 128-156.

22. Gentner TQ, Fenn KM, Margoliash D, Nusbaum HC (2006) Recursive syntactic pattern learning by songbirds. Nature 440: 1204-1207.

23. Goller F, Suthers RA (1995) Implications for lateralisation of birdsound from unilateral gating of ipsilateral motor patterns. Nature 373: 63-66.

24. Nottebohm F (1971) Neural lateralization of vocal control in a passerine bird. I. Song. J. Exp. Zool. 177: 229-262.
25. Nottebohm F (1971) Neural lateralization of vocal control in a passerine bird. II Subsong, calls and a theory of vocal learning. J. Exp. Zool. 179: 35-50.

26. Suthers RA (1990) Contributions to birdsong from the left and right sides of the intact syrinx. Nature 347: 473-477.

27. Suthers RA (1998) Peripheral control and lateralization of birdsong. J. Neurobiol 33: $632-652$.

28. Josephson RK (1985) The mechanical power output from striated muscle during cyclic contraction. J Exp Biol 114: 493-512.

29. Rome LC, Syme DA, Hollingworth S, Lindstedt SL, Baylor SM (1996) The whistle and the rattle: The design of sound producing muscles. Proc Natl Acad Sci USA 93: 8095-8100.

30. Rome LC, Cook C, Syme DA, Connaugthon MA, Ashley-Ross M, Klimov A, Tikunov B, Goldman YE (1999) Trading force for speed: Why superfast crossbridge kinetics leads to superlow forces. Proc Natl Acad Sci USA 96: 5826-5831.

31. Young IS, Rome LC (2001) Mutually exclusive designs: the power output of the locomotory and sonic muscles of the oyster toadfish (Opsanus tau). Proc R Soc Lond B 268: 1965-1070.

32. Parmentier E, Genotte V, Focant B, Goffinet G, Vandewalle P (2003) Characterization of the primary sonic muscles in Carapus acus (Carapidae): a multidisciplinary approach. Proc Roy Soc B 270: 2301-2308.

33. Fine ML, Mallow KL, King CB, Mitchell SL, Cameron TM (2001) Movement and sound generation by the toadfish swim bladder. J Comp Phys A 187: 371-379.

34. Conley KE, Lindstedt SL (1996) Minimal cost per twitch in rattlesnake tail muscle. Nature 383: 71-72.

35. Hoh JFY (2005) Laryngeal fiber types. Acta Physiol Scan 183: 133-149.

36. Briggs MM, Schachat F (2000) Early specialization of the superfast myosin in extraocular and laryngeal muscles. J Exp Biol 203: 2485-2494.

37. Close RI, Luff AR (1974) Dynamic properties of inferior rectus muscle of the rat. J Physiol 236: 259-270.

38. Rome LC, Lindstedt SL (1998) The quest for speed: muscles built for highfrequency contractions. News Physiol Sci 13: 261-268.

39. Syme DA, Josephson RK (2002) How to build fast muscles: synchronous and asynchronous designs. Integ Comp Biol 42: 762-770.

40. Alexander RM (1989) Optimization and gaits in the locomotion in vertebrates. Physiol Rev 69: 1199-1227.

41. Williams H (2004) in Behavioral Neurobiology of Birdsong, Zeigler HP, Marler P, eds. Annals New York Acad Sci 2004, pp 1-30.

42. Wade J, Arnold AP (2004) in Behavioral Neurobiology of Birdsong, Zeigler HP, Marler P, eds. Annals New York Acad Sci 2004, pp 540-559.

43. Trevisan MA, Cooper B, Goller F, Mindlin GB (2007) Lateralization as a symmetry breaking process in birdsong. Phys. Rev. E 75: 031908(5).

44. Suthers RA, Goller F, Hartley RS (1994) Motor dynamics of song production by mimic thrushes. J Neurobiol 25: 917-936.

45. Tchernichovski O, Nottebohm F, Ho CE, Pesaran B, Mitra PP (2000) A procedure for automated measurement of song similarity. Anim Beh 59: 1167-1176.

46. Larsen ONL, Goller F (2002) Direct observation of syringeal muscle function in songbirds and a parrot. J. Exp. Biol. 205: 25-35. 